First Peoples Child \& Family Review

A Journal on Innovation and Best Practices in Aboriginal Child Welfare Administration,

Research, Policy \& Practice

\title{
POEM: Can You Hear Me Through the White Noise?
}

\section{Laurie Harding}

Volume 4, Number 1, 2009

URI: https://id.erudit.org/iderudit/1069344ar

DOI: https://doi.org/10.7202/1069344ar

See table of contents

Publisher(s)

First Nations Child and Family Caring Society of Canada

ISSN

1708-489X (print)

2293-6610 (digital)

Explore this journal

Cite this document

Harding, L. (2009). POEM: Can You Hear Me Through the White Noise? First Peoples Child \& Family Review, 4(1), 9-9. https://doi.org/10.7202/1069344ar viewed online.

https://apropos.erudit.org/en/users/policy-on-use/ 


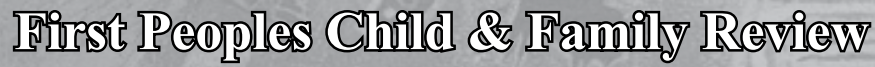

A Journal on Innovation and Best Practices in Aboriginal Child Welfare Administration, Research, Policy \& Practice

\section{Volume 4, Number 1, 2009, p. 9}

\section{POEM: Can You Hear Me Through the White Noise?}

Laurie Harding

Can you Hear what I am telling you?

When I look away,

When I don't answer,

When I look blankly through you?

Do you Want to know?

Or is it too uncomfortable?

Too awkward?

Too ugly?

Speak to me with your Eyes,

Your Heart,

Your Soul,

Your Being.

Can you, hear me, see me, Feel my Pain?

Are you Worth my time?

Or is this all the same boring Rhetoric?

Hearing your-Self speak?

Already hearing what You want to know.

Validating

Measuring

Quantifying,

Proving Your point.

What about Mine?

Does it even matter,

Do I? 